\title{
Penerapan teknologi hidroponik sistem deep flow technique sebagai usaha peningkatan pendapatan petani di Desa Sungai Bawang
}

\author{
Fitmawati $^{\star 1}$, Isnaini ${ }^{2}$, Siti Fatonah ${ }^{1}$, Nery Sofiyanti ${ }^{1}$, dan Rodesia Mustika \\ Roza ${ }^{1}$
}

\author{
1Jurusan Biologi, Fakultas Matematika dan Ilmu Pengetahuan Alam, Universitas Riau \\ 2Jurusan Agroteknologi, Fakultas Pertanian, Universitas Riau
}

* fitmawati@lecturer.unri.ac.id

\begin{abstract}
The target becomes a self-reliant village must be accompanied by strengthening village ability in supplying the basic needs independently. Vegetables are one of the crucial basic needs to achieve a healthy and prosperous society. The demand for vegetables in Sungai Bawang Village, Kuantan Singingi Regency, is constrained by the available land for vegetable farming. Hydroponic planting system offers the technique without soil that can be implemented anywhere. It has added value in providing clean and hygienic vegetables. Hydroponics technology system of Deep Flow Technique able to provide water and oxygen for plants and suitable for leafy vegetables. Hydroponic is appropriate to be implemented in Sungai Bawang village and did not require huge land in applying this technology. The mentoring strategy is carried out by counseling and demonstration of direct planting stages and the practice by the community. This activity gave a positive influence on the community as well as many people who want to apply this technology. This was the first step in increasing the income of the community, especially farmers. And for the community in general, this technology facilitates the people to get vegetables easily at an affordable price.
\end{abstract}

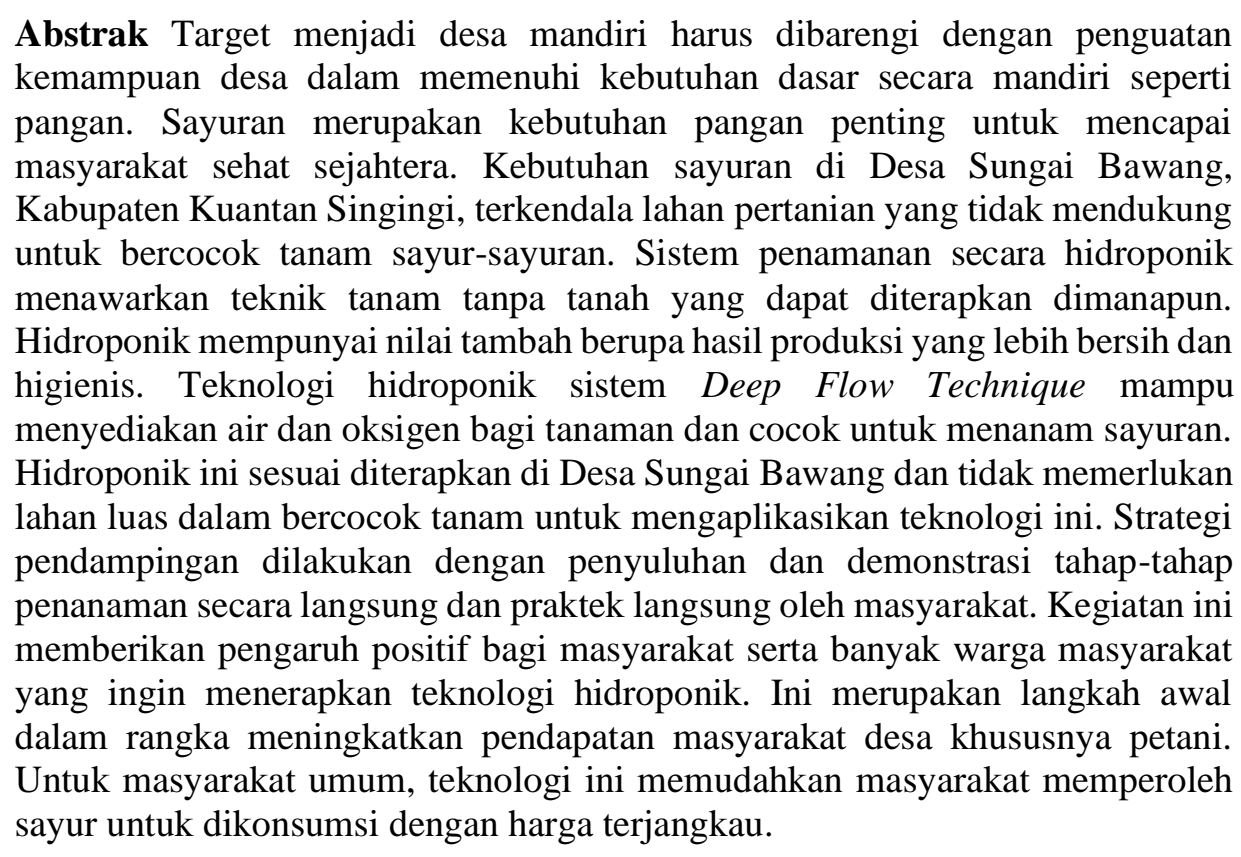

\section{ठ OPEN ACCESS}

Citation: Fitmawati, Isnaini, S. Fatonah, N. Sofiyanti, dan R. M. Roza. 2018. Penerapan teknologi hidroponik sistem Deep Flow Technique sebagai usaha peningkatan pendapatan petani di Desa Sungai Bawang Riau Journal of Empowerment 1(1): 23-29 https://doi.org/10.31258/raje.1.1.3

Received: 2018-07-29, Accepted: 2018-08-09

Language: Bahasa Indonesia (id)

Funding: Kegiatan pengabdian kepada masyarakat ini didanai oleh Lembaga Penelitian dan Pengabdian kepada Masyarakat Universitas Riau (skema hibah Pengabdian kepada Masyarakat) dengan nomor kontrak 1262/UN.19.5.1.3/PP/2018

(C) 2018 Fitmawati et al. The article by Author(s) is licensed under a Creative Commons

Attribution 4.0 International License. This license permits unrestricted use, distribution, and reproduction in any medium, provided the original author and source are credited. 
Keywords: hydroponics; deep flow technique; hygienic vegetables; Kuantan Singingi

\section{PENDAHULUAN}

Kemandirian (swasembada) pangan adalah cita-cita agung yang harus diwujudkan dengan upaya dari berbagai pihak, karena mandiri dalam pemenuhan kebutuhan dasar manusia ini adalah hakikat kemerdekaan sesungguhnya. Swasembada pangan dalam sebuah rumah tangga adalah kondisi terpenuhinya pangan bagi rumah tangga yang tercermin dari ketersediaan pangan yang cukup, baik jumlah maupun mutunya, aman, merata dan terjangkau [5]. Pendalaman swasembada pangan ditingkat rumah tangga sangat penting untuk mengatasi dinamika rawan pangan secara lokal [7]. Desa Swasembada pangan harus didukung dengan ketahanan sumber daya manusia (SDM) sebagai pengelola dan sumber daya ruangnya sebagai media yang sudah tersedia dan dari alam.

Desa Sungai Bawang awalnya merupakan desa binaan Departemen Transmigrasi dengan nama Unit Pemukiman Transmigrasi (UPT) dengan komoditas perkebunan kelapa sawit. Pada tahun 1998, Desa Sungai Bawang menjadi desa definitif dan pada tahun 1999 desa ini masuk wilayah Kecamatan Singingi Kabupaten Kuantan Singingi, Provinsi Riau. Desa ini memiliki luas wilayah pemukiman $114 \mathrm{Ha}$, luas perkebunan $650 \mathrm{Ha}$, luas perkantoran 2,69 Ha, Luas sekolah $0,50 \mathrm{Ha}$ dan jalan $8,50 \mathrm{Ha}$. Mata pencaharian masyarakat didominasi oleh petani sawit dan karet (400 orang) dan pedagang (72 orang). Oleh karena itu, sektor perkebunan menjadi andalan masyarakat di daerah ini di samping sektor lainnya. Permasalahan utama di desa ini adalah ketergantungan sumber pangan berupa bahan pokok dan sayur-mayur yang harus dipasok dari luar daerah, sehingga ketersediaan yang sedikit dan harga yang [6].

Budidaya tanaman secara hidroponik merupakan teknologi pertanian modern khususnya tanaman hortikultura. Hidroponik adalah salah satu cara bercocok tanam tanpa menggunakan tanah sebagai media tanam. Teknologi ini merupakan salah satu cara budidaya tanaman menggunakan prinsip penyediaan larutan hara sesuai dengan kebutuhan tanaman. Pada awalnya, istilah hidroponik hanya ditujukan untuk menggambarkan cara menumbuhkan tanaman dalam sistem air, akan tetapi saat ini mencakup semua sistem yang menggunakan larutan hara baik dengan penambahan medium inert maupun tidak (seperti pasir, kerikil, rockwool, vermikulit) untuk dukungan mekanis [1,2]. Hidroponik adalah cara bercocok tanam alternatif di wilayah dengan lahan pertanian yang terbatas. Salah satu contoh teknologi hidroponik yaitu Deep Flow Technique (DFT).

Hidroponik sistem DFT merupakan salah satu metode kultur menggunakan air sebagai media dan persediaan nutrisi. Prinsip kerja teknologi DFT yaitu mensirkulasi larutan nutrisi dan aerasi secara kontiniu selama 24 jam pada rangkaian aliran tertutup [4, 10]. Keuntungan sistem DFT adalah penanaman dengan kebutuhan nutrisi yang cukup sedikit dan memiliki sistem aerasi yang baik dengan air setinggi $2 \mathrm{~cm}$ dan disertai adanya rongga udara yang menyediakan oksigen bagi tanaman dengan aerasi yang dibantu oleh mesin pompa air. Dengan adanya rongga udara di dalam sistem sangat membantu dalam mengurangi resiko tidak adanya pergerakan air akibat tidak ada daya listrik, sehingga tanaman tidak mudah terpengaruh dan dalam jangka pendek kebutuhan oksigen tetap dapat terpenuhi. Sistem ini merupakan salah satu metode bercocok tanam yang mudah dan tidak membutuhkan biaya yang besar dan sangat ideal untuk menanam sayuran (leafy vegetables) [9, 3]. Metode ini dapat digunakan untuk budidaya tanaman secara agronomis dan ekonomis yang menguntungkan, sehingga dapat membantu meningkatkan pendapatan petani khususnya di wilayah pedesaan dengan lahan yang kurang mendukung.

Tujuan penerapan teknologi hidroponik sistem DFT ini guna mendukung usaha peningkatkan produktivitas petani sayur-mayur sehingga tidak perlu didatangkan dari luar daerah sehingga meningkatkan daya saing produk sayuran tersebut, selain itu produk sayuran ini yang lebih bersih dan higenis, serta dapat diproduksi secara masal dalam memenuhi permintaan pasar, yang pada akhirnya dapat meningkatkan pendapatan masyarakat petani di Desa Sungai Bawang, Kecamatan Singingi, Kabupaten Kuantan Singingi. 


\section{MASALAH}

Fitmawati dkk.

Sungai Bawang adalah sebuah desa di Kecamatan Singingi Kabupaten Kuantan Singingi dimana mata pencarian masyarakat pada umumnya adalah petani perkebunan dengan komoditas utama kelapa sawit. Ketersediaan sayur-mayur segar dan murah sangat diperlukan di Desa Sungai Bawang yang selama ini dipasok dari luar daerah. Salah satu upaya peningkatan suplai sayuran adalah dengan teknologi penanaman sayur hidroponik sistem Deep Flow Technique (DFT) yang lebih bersih, higienis dan dapat diproduksi secara masal guna meningkatkan pendapatan masyarakat. Selain itu, hidroponik ini sangat sesuai diterapkan pada lahan marginal seperti di Desa Sungai Bawang dan tidak memerlukan lahan yang luas dalam mengaplikasikan teknologi hidroponik. Tolak ukur ketercapaian kegiatan ini adalah dapat membuka wawasan masyarakat Desa Sungai Bawang, tentang pentingnya mengatasi permasalahan pasokan sayur-sayuran di desa tersebut, sehingga masyarakat tertarik untuk mengaplikasikan teknologi hidroponik yang telah dijelaskan dan dipraktikkan secara langsung.

\section{METODE}

\section{Waktu dan tempat}

Kegiatan pengabdian ini dilaksanakan pada 8 Juli 2018 di Desa Sungai Bawang Kecamatan Singingi, Kabupaten Kuantan Singingi. Penerapan teknologi hidroponik sistem DFT yang telah disosialisasikan oleh mahasiswa dan dosen Biologi kepada masyarakat terus dilanjutkan sampai masa panen. Acara pengabdian ini dipersiapkan dan dibantu pelaksanaanya oleh mahasiswa Kuliah Kerja Nyata (KKN) Universitas Riau tahun 2018.

\section{Metode pelaksanaan}

Metode penerapan kegiatan pembinaan di Desa Sungai Bawang Kecamatan Singingi Kabupaten Kuantan Singingi dilakukan dengan beberapa tahapan diantaranya yaitu:

a. Pembinaan masyarakat sasaran terhadap pentingnya tanaman pangan untuk memenuhi kebutuhan sehari-hari.

b. Penyuluhan kepada masyarakat sasaran dengan memberikan materi tentang teknologi hidroponik sistem DFT.

c. Demonstrasi dan pembinaan masyarakat sasaran dalam pembuatan media tanam hidroponi sebagai bahan percobaan pertama.

d. Pelatihan dan praktek di lapangan mengenai teknologi hidroponik

e. Pembuatan instalasi hidroponik sistem DFT dan penanaman benih dalam media tanam yang telah dibuat oleh masayarakat ke instalasi hidroponik sistem DFT.

f. Melakukan monitoring dan pendampingan agar teknologi yang disampaikan betul-betul diaplikasikan oleh masyarakat. Masyarakat melakulan perawatan sampai sayur yang ditanam dapat dipanen.

g. Dilakukan Evaluasi pada bulan berikutnya untuk melihat perkembangan lahan percobaan dan partisipasi masyarakat dalam mengaplikasikan teknologi hidroponik.

h. Indikator keberhasilan yaitu masyarakat sasaran berhasil panen sayu-sayuran yang ditanam dari teknologi hidroponik sistem DFT. 


\section{PEMBAHASAN}

\section{Kondisi Desa}

Desa Sungai Bawang Kecamatan Singingi Kabupaten Kuantan Singingi merupakan desa transmigrasi dengan mata pencaharian utama perkebunan monokultur kelapa sawit dengan pendapatan yang sedang-tinggi. Berdasarkan data luasan lahan perkebunan kelapa sawit di desa ini adalah sebesar 454 Ha dengan tipe tanah Podsolik Merah Kuning (PMK) [6]. Kondisi ini mengakibatkan sulit dikembangkanya produk pertanian lainya seperti sayur-mayur. Kebutuhan sayuran di Desa Sungai Bawang sangat bergantung pada pasokan dari luar daerah dengan harga yang cukup tinggi sehingga sayuran merupakan barang mahal di daerah ini.

\section{Deep Flow Technique (DFT)}

Teknologi hidroponik DFT menggunakan meja baja tempat instalasi hidroponik yang diberi naungan (Gambar 1). Tanaman yang ditanam diletakkan di atas larutan nutrisi yang terapung dalam net pot (wadah penanaman). Benih ditanam pada lubang styrofoam dengan media rock wall kemudian diapungkan di atas larutan nutrisi. Dalam sistem ini, larutan memiliki peran yang sangat penting untuk pertumbuhan dan kualitas hasil tanaman agar tanaman tumbuh optimal, komposisi dan jumlah unsur hara harus sesuai dengan kebutuhan tanaman [8]. Sistem DFT adalah penanaman dengan kebutuhan nutrisi yang tepat dan memiliki sistem aerasi yang baik dengan kebutuhan air yang tidak banyak hanya setinggi $2 \mathrm{~cm}$. Pergerakan air menggunakan mesin pompa air guna menyediakan airasi yang baik bagi tanaman (Gambar 2).

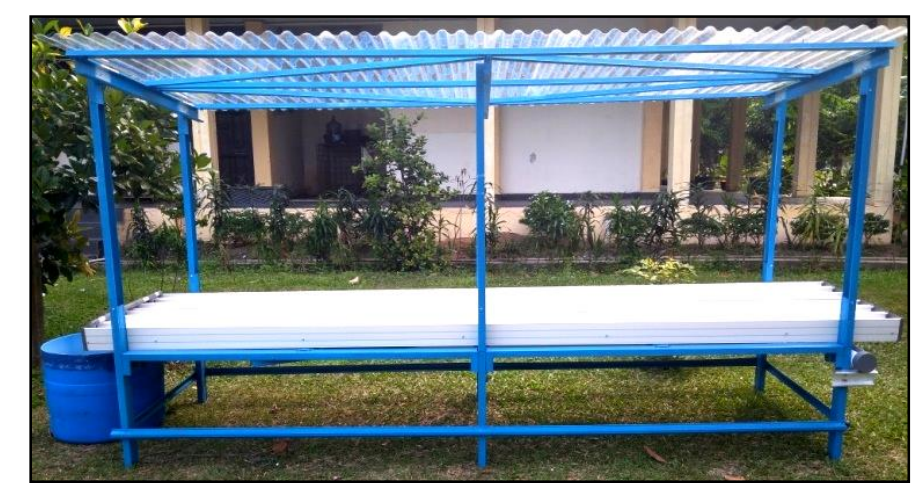

Gambar 1. Instalasi teknologi hidroponik sistem DFT

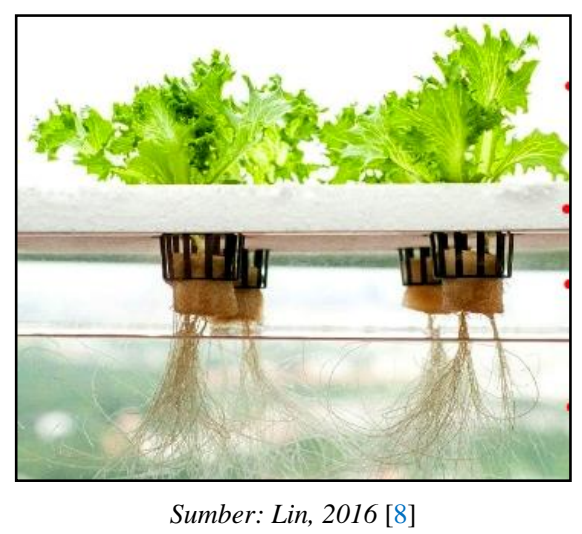

Gambar 2. Sistem penanaman hidroponik DFT

Adapun perangkat teknologi hidroponik DFT yang telah dirancang meliputi:

1. Meja dengan kerangka baja dengan ukuran 4x105 cm, tinggi $80 \mathrm{~cm}$ sebagai tempat instalasi hidroponik.

2. Atap dari seng plastik bening berfungsi untuk penutup meja melindungi tanaman dari sinar matahari dan hujan.

3. Mesin Pompa air digunakan untuk sistem drainase hidroponik.

4. Pipa apung beserta perangkatnya digunakan untuk menampung air dan nutrisi hidroponik. 
5. Styrofoam dilubangi dengan jumlah total 300 lubang. Busa steroform digunakan untuk meletakkan netpot atau wadah tanaman dan menahannya agar posisinya tetap stabil. sterofoam dilubangi sesuai dengan ukuran netpot atau pot tanaman yang akan dimasukkan kedalamnya.

6. Netpot (Pot Hidroponik) digunakan untuk menyimpan tanaman di dalam instalasi hidroponik.

7. Rockwool adalah media tanam hidroponik yang umumnya terbuat dari kombinasi batuan basalt, batu batu kapur dan batu baru yang dipanaskan dengan suhu yang tinggi. Bentuknya seperti serabut-serabut halus.

\section{Pelatihan dan Pembinaan kepada Masyarakat}

Masyarakat Desa Sungai Bawang memiliki potensi dalam mengembangkan keahliannya dalam bercocok tanam. Upaya pengembangan ini penting dilakukan untuk mengatasi permasalahan sulitnya memenuhi kebutuhan sayuran di desa tersebut, dimana kebutuhan sayuran masyarakat dipasok dari luar daerah dengan harga yang cukup mahal samapi di desa dan sayuran menjadi kurang segar lagi. Selain itu, kurangnya aktifitas masyarakat terutama Ibu-ibu rumah tangga sangat mendukung adanya beberapa kegiatan untuk mengisi waktu keseharian yang memberikan manfaat yaitu dengan bercocok tanam.

Untuk memenuhi kebutuhan sayur-sayuran di Desa Sungai Bawang diharapkan masyarakat mampu memproduksi sayur sendiri dengan cara bercocok tanam baik skala rumah tangga maupun untuk produksi besar. Akibat kendala tanah yang miskin hara maka diperlukan inovasi baru dalam teknik budidaya salah satunya adalah dengan teknologi hidroponik. Hidroponik sangat sesuai diterapkan pada lahan marginal seperti di Desa Sungai Bawang dan tidak memerlukan lahan yang luas dalam mengaplikasikan teknologi ini. Upaya ini kemudian dapat dijadikan sebagai usaha peningkatan pendapatan masyarakat.
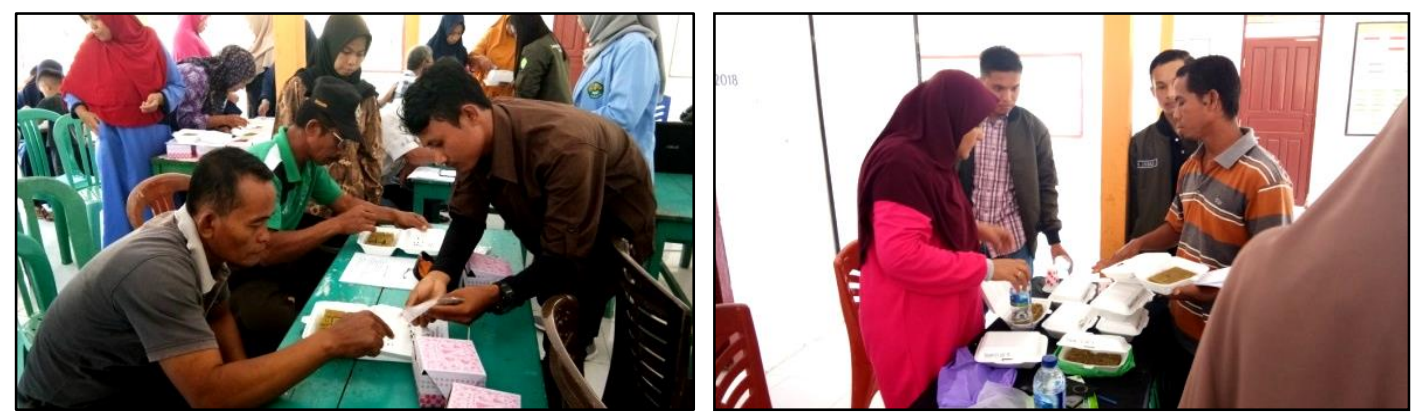

Gambar 3. Peserta pelatihan melakukan penanaman benih di media tanam rockwol

Dengan adanya kegiatan ini diharapkan dapat menambah pengetahuan dan keterampilan masyarakat dalam bercocok tanam, teknologi yang diaplikasikan ini dapat memudahkan masyarakat mencukupi kebutuhan sayur-sayuran untuk dikonsumsi dengan harga yang terjangkau. Aplikasi skala besar dapat juga menjadi sumber penghidupan masyarakat desa, sehingga akan membantu dalam peningkatan pendapatan masyarakat Desa Sungai Bawang. Adapun tanaman sayur-sayuran yang ditanam dalam kegiatan ini adalah kangkung, pakcoy, sawi dan bayam. Masyarakat langsung praktek menanam benih-benih tersebut pada media tanam rockwool pada styrofoam (Gambar 3).

Berdasarkan hasil jawaban kuosioner masyarakat, menunjukkan bahwa masyarakat Desa Sungai Bawang belum mengetahui teknologi hidroponik dengan persentase $100 \%$. Seluruh masyarakat bersemangat untuk mencoba mengaplikasikan metode ini dalam skala rumah tangga yang murah dan ramah lingkungan dengan persentase $100 \%$. Sebelumnya masyarakat belum pernah mencoba teknologi hidroponik ini (100\%). Pengenalan langsung dengan perangkat sistem hidroponik DFT memberikan respon yang baik dan antusias dari masyarakat (Gambar 4). 

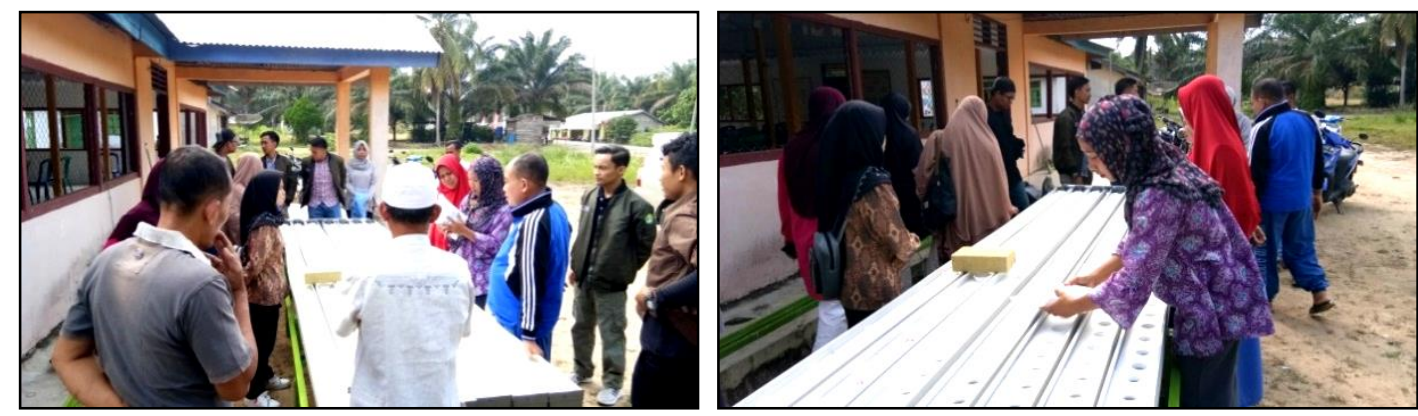

Gambar 4. Pengenalan perangkat hidroponik DFT kepada masyarakat Desa Sungai Bawang

\section{Pemeliharaan dan Masa Panen}

Pemeliharaan dan pengawasan tanaman yang telah disemai bersama petani pada acara pelatihan tiga minggu sebelumnya dilakukan oleh mahasiswa KKN Universitas Riau periode 2017/2018 Perawatan dan pemeliharaan ini meliputi pemantauan terhadap kondisi aerasi, bak penampungan, media tanam dan larutan nutrisi, menjaga sanitasi lingkungan. Pemeliharaan dari hama dan penyakit pada sistem hidroponik ini dilakukan dengan pengendalian hayati tanpa menggunakan pestisida, seperti membersihkan tanaman yang terserang hama dan penyakit.

Masa panen sayur yang ditanam dengan sistem hidroponik DFT kurang lebih dua minggu setelah masa tanam. Hasil panen pertama yang diperoleh adalah tanaman kangkung (Gambar 5). Walaupun masih sedikit hasil panen yang diperoleh, namun masyarakat merasa puas dan tertarik untuk mengembangkan metode ini dan tidak hanya akan berakhir setelah panen perdana tersebut.
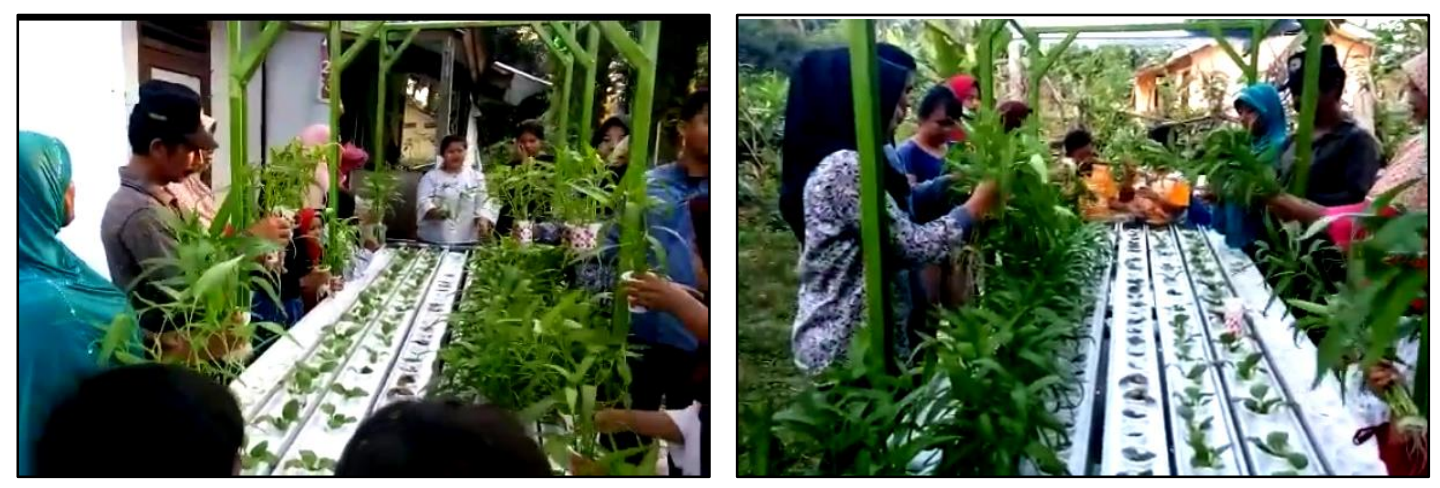

Gambar 5. Tanaman kangkung hasil panen oleh masyarakat

Kegiatan pembinaan yang dilaksanakan ini menunjukkan pengaruh positif bagi masyarakat. Adanya kegiatan ini membuat peserta merasa dapat mengisi waktu luang dengan aktivitas yang lebih bermanfaat karena memperoleh ilmu dan wawasan baru bagi masyarakat maupun lingkungan sekitarnya. Pelatihan penerapan teknologi hidroponik ini merupakan langkah awal dalam rangka peningkatan ketersediaan sayur-sayur bersih, higienis, dan murah serta dapat meningkatkan pendapatan masyarakat khususnya petani.

\section{KESIMPULAN}

Pelatihan dan penerapan teknologi hidroponik sistem DFT sebagai usaha peningkatan pendapatan petani di Desa Sungai Bawang, Kecamatan Singingi, Kabupaten Kuantan Singingi telah berhasil membuka wawasan petani akan adanya sistim alternatif dalam budidaya sayurmayur. Pada acara pengabdian ini masyarakat menunjukkan rasa antusiasnya dan menyatakan ingin mengaplikasikan teknologi ini. Peserta kegiatan memperoleh pengetahuan dan wawasan penerapan teknologi hidroponik dan merupakan langkah awal dalam rangka meningkatkan pendapatan masyarakat khususnya petani. Dan untuk masyarakat secara umum, teknologi ini 
dapat memudahkan masyarakat memperoleh sayur-sayuran untuk dikonsumsi dengan harga yang terjangkau.

\section{UCAPAN TERIMA KASIH}

Penulis mengucapkan terimakasih kepada Lembaga Penelitian dan Pengabdian kepada Masyarakat Universitas Riau skema hibah Pengabdian kepada Masyarakat tahun anggaran 2018 yang telah mendanai dalam pelaksanaan kegiatan pengabdian dengan nomor kontrak 1262/UN.19.5.1.3/PP/2018 dan seluruh Mahasiswa KKN Universitas Riau tahun 2018 di Desa Sungai Bawang, Kecamatan Singingi, Kabupaten Kuatan Singingi.

\section{Daftar Pustaka}

1. Anas, D.S., dan Y. Koerniawati. 2004. Pengaruh valume dan jenis media tanam pada pertumbuhan dan hasil tanaman Selada (Lactuca sativa) dalam teknologi hidroponik sistem terapung. Dalam Kongres dan seminar nasional perhimpunan Hortikultura Indonesia (PERHORTI), Jakarta, 22 September 2004. Fakultas Pertanian Institut Pertanian Bogor.

2. Anas, D.S. 2013. Teknik Hidroponik. Bogor: Institut Pertanian Bogor.

3. Assimakopoulou, A., A. Kotsiras, and K. Nifakos. 2013. Incidence of Lettuce Tipburn as Related to Hydroponic System and Cultivar. Journal of Plant Nutrition 36(9). https://doi.org/10.1080/01904167.2013.793709

4. Atmaja, F.D. 2009. Analisis Keseimbangan Panas pada Bak Penanaman dalam Sistem Hidroponik Deep Flow Technique (DFT). Bogor: Fakultas Teknologi Pertanian, Institut Pertanian Bogor.

5. Darsono. 2012. Faktor Utama Swasembada Pangan Tingkat Rumah Tangga Petani Lahan Kering di Kabupaten Wonogiri Provinsi Jawa Tengah. SEPA 9(1): 100-116.

6. Data Profil Desa. 2018. Profil Desa Sungai Bawang Kecamatan Singingi Kabupaten Kuantan Singingi, Provinsi Riau.

7. Dekasari, D.A. 2016. Pemberdayaan Petani dalam Meningkatkan Ketahanan Pangan di Desa Sambiroto, Kecamatan Padas, Kabupaten Ngawi. Jurnal Analisa Sosiologi 5(1): 38-50.

8. Lin, J.C.Y.J. 2016. DFT Deep Flow Technique. Unisoft S.A. Brasileiro De Hidroponia. Floriandopolis Santa Ctarina. http://www.encontrohidroponia.com.br/images/site/palestras/5_Juan_Carlos.pdf. Diakses pada 8 Mei 2018.

9. Mansyur, A.N., S. Triyono, dan A. Tusi. 2014. Pengaruh Naungan terhadap Perumbuhan Sawi (Brassica juncea L.) pada Sistem Hidroponik DFT (Deep Flow Technique). Jurnal Teknik Pertanian Lampung 3(2): 103-110.

10. Ningrum, D.Y., S. Triyono, dan A. Tusi. 2014. Pengaruh Lama Aerasi Terhadap Pertumbuhan dan Hasil Tanaman Sawi (Brassica Juncea L.) pada Hidroponik DFT (Deep Flow Technique). Jurnal Teknik Pertanian Lampung 3(1): 83-90. 